\title{
Investigating the Prevalence of Low Bone Mass in Children of Southern Iran and Its Associated Factors
}

\author{
Forough Saki, ${ }^{1}$ Gholamhossein Ranjbar Omrani, ${ }^{1}$ Marjan Jeddi, ${ }^{1}$ Marzie Bakhshaieshkaram, ${ }^{2}$ and \\ Mohammad Hossein Dabbaghmanesh ${ }^{3, *}$ \\ ${ }^{1}$ Shiraz Endocrinology and Metabolism Research Center, Shiraz University of Medical Sciences, Shiraz, Iran \\ ${ }^{2}$ Endocrine and Metabolism Research Center, Shiraz University of Medical Sciences, Shiraz, Iran \\ ${ }^{3}$ Shiraz Endocrinology and Metabolism Research Center, Endocrinologist, Shiraz University of Medical Sciences, Shiraz, Iran \\ "Corresponding author: Mohammad Hossein Dabbaghmanesh, Endocrinology and Metabolism Research Center, Nemazee Hospital, P.O. Box 71345-1744, Shiraz, Iran. Tel/Fax: \\ +98-7136473268, E-mail: dabbaghm@sums.ac.ir
}

Received 2017 February 01; Revised 2017 March 27; Accepted 2017 July 03.

\begin{abstract}
Background: Improving peak bone mass and bone strength in the first years of life and enhancing it during young adulthood could prevent osteoporosis and fractures in the last years of life. We evaluated the prevalence of low bone mass in the lumbar and femoral neck and its associated factors in southern Iranian children.

Methods: This is a cross-sectional study on healthy Iranian children aged 9 - 18 years old during 2011 - 2012. Dual energy X-ray absorptiometry (DEXA) was used for measuring bone mineral density (BMD). BMD Z-score $\leq-2$ was considered as low. Anthropometric data, physical activity, sun exposure, puberty, and mineral biochemical parameters were assessed. Data were analyzed using SPSS v.15.

Results: 477 normal children, including 236 (49.5\%) girls and 241 (50.5\%) boys, aged $13.8 \pm 2.7$ years were enrolled. Prevalence of low bone mass (LBM) in the femoral and lumbar region was $10.7 \%$ and $18.7 \%$, respectively. The prevalence of LBM in femur of girls is twice more than boys. Fat mass index, BMI Z-score, and physical activity were associated with lumbar low bone mass. BMI Z-score and physical activity were associated with femoral low bone mass.

Conclusions: High prevalence of low bone mineral density in children 9 to 18 years in south of the country is concerned and is needed to plan for prevention and treatment. BMI-Z score, fat mass index, and physical activity were the 3 most important preventive factors in developing low bone mass in children.
\end{abstract}

Keywords: Children, Iran, BMI, Bone Mineral Density

\section{Background}

The base of lifelong skeletal health is accumulated during childhood and adolescence (1). Nearly 90\% of adult bone mass is accumulated before the age of 20 (2), so improving peak bone mass and bone strength in the first years of life as well as enhancing it during young adulthood could prevent osteoporosis and fractures in the last years of life (3). More understanding regarding the prevalence of low bone mass (LBM) and factors influencing the measuring bone mineral density (BMD) in childhood could help us to achieve optimal peak bone density (4). Dual energy X-ray absorptiometry (DEXA) is the method of choice for BMD due to its high accuracy and low radiation exposure (5). Interpretation of densitometric data in children should be done by Z-score assessment, which was matched for the age and sex of patient. Values below -2 are generally considered low bone mass and it is a serious warning of future osteoporosis and bone fragility (6). Previous reports showed that bone density in black sub- jects was more than the whites, and it is low in Chinese and Japanese population $(7,8)$. Furthermore, Caucasian children, similar to Spanish ones, had a higher lumbar spine BMD than finish children (4), therefore geographical differences could change the BMD of children. There are some controversies regarding the factors affecting the BMD of children such as age, puberty, sex, calcium intake, physical activity, body weight, sun exposure, and body composition in different population (3, 4, 6, 9-17). Previously, we investigated the normative data of children in the Fars Province (18). However, to the best of our knowledge, there is lack of data regarding the prevalence of low bone mass for chronological age and its associated factors in Iranian children.

The purpose of this study was to evaluate the prevalence of low bone mass in the lumbar and femoral neck in Iranian children and investigate the relationship of low bone mass with the sex, Body mass index(BMI), age, puberty, physical activity, and body composition of these chil- 
dren. This study was performed in the Endocrinology and Metabolism Research Center, Shiraz University of Medical Sciences.

\section{Methods}

\subsection{Population}

This is a cross-sectional study performed in Kawar, an urban area located $50 \mathrm{~km}$ east of Shiraz in South of Iran, during 2011 - 2012. A continuum of a prospective survey was started by evaluation of the normative data of BMD in healthy Iranian children aged 9-18 years old (18). It was performed on healthy Iranian children aged 9-18 years old. An age-stratified systematic random sample of $7.5 \%$ was used, and 500 children (250 girls, 250 boys) were selected for the study. Children who had a known systemic disease (e.g. diabetes and renal failure), using medications (e.g. steroids), and had a history of precocious or delayed puberty were excluded from the study; in addition, 7 children refused to do densitometry. Ultimately, 477 children did the study to the end. The ethics committee of our University approved our study with the Grant No.89-5127. Parents singed the informed consent form.

\subsection{Anthropometric Data, Physical Activity, Sun Exposure and Pubertal Stage}

A trained physician measured the children's height and weight with standard methods using a wall mounted meter and a standard scale (Seca, Germany), respectively. Body mass index (BMI) was calculated trough this formula: BMI $\left(\mathrm{kg} / \mathrm{m}^{2}\right)=$ weight $(\mathrm{kg}) /(\text { height }(\mathrm{m}))^{2}$. Pubertal stage was evaluated according to the tanner standard classification (18). A written questionnaire related to activity, sun exposure, calcium intake, birth weight, and previous fracture was gathered from the parents. According to American College of Sports Medicine recommendation (18), we divided the children into 2 groups, whether they performed physical activities fewer or more than 3 times per week. According to their average exposure to sunshine per day, we classified the children into 3 groups, those exposed for: $<15$ $\mathrm{min} /$ day, 15-30 $\mathrm{min} /$ day and those exposed for $>30 \mathrm{~min} /$ day (18).

\subsection{Mineral Biochemical Parameters}

One experienced technician took all the blood samples in the Shiraz endocrinology research center after 8 12 hours of fasting. Serum calcium (Ca), phosphorous (P), and alkaline phosphatase (ALP) were checked by colorimetric assay with an auto-analyzer (Biosystems SA, Barcelona,
Spain). Furthermore, we checked the concentration of 25hydroxy vitamin D (25OHD) during autumn by high performance liquid chromatography (young lee 9100, South Korea) in $\mathrm{ng} / \mathrm{mL}$. The normal range for calcium was 8.5 - 10 $\mathrm{mg} / \mathrm{dL}$, phosphorus $3.7-5.4 \mathrm{mg} / \mathrm{dL}$ up to 15 years of age and 2.5 - $4.5 \mathrm{mg} / \mathrm{dL}$ for ages 16 years and older, and that of 25hydroxy vitamin D was 20 - $80 \mathrm{ng} / \mathrm{mL}$. Normal ALP levels in adults are considered $20-140 \mathrm{Iu} / \mathrm{L}$, though it is higher in children.

\subsection{Measurement of BMD and Body Composition}

Hologic system DEXA (Discovery QDR, USA) was used for measuring bone mineral density and body composition. The normative data for interpreting healthy children were from the standard data of Hologic system DEXA (Discovery QDR, USA), which was from the U.S. Centers for disease control's "national health and nutrition examination survey" (NHANES). The coefficient of variation in our laboratory was $2.4 \%$ for the femoral neck and $0.51 \%$ for the lumbar spine based on measurements in 10 children. Bone mineral density $\left(\mathrm{g} / \mathrm{cm}^{2}\right) \mathrm{Z}$ score of less than -2 for the patient's age and sex were considered as low bone mass (LBM). Fat mass index $\left(\mathrm{kg} / \mathrm{m}^{2}\right)$ (Total fat mass $(\mathrm{kg}) /$ (height $(\mathrm{m}))$ ) and lean mass index $\left(\mathrm{kg} / \mathrm{m}^{2}\right)$ (Total lean mass $(\mathrm{kg}) /$ (height $(\mathrm{m}))^{2}$ was calculated by the DEXA system, automatically. DEXA was performed when the child was wearing special clothing without shoes.

\subsection{Statistical Analysis}

Height, weight, age, and DEXA outputs were checked for normal distribution by one sample Kolmogorovsimirnov test. A t-test was used for normal distributed data and Mann-Whitney test used for others. The association of low bone mass with all the variables, which had $\mathrm{P}$ value less than 0.2 in univariate analysis, was analyzed in a backward step wise mode multiple regression analysis to exclude the confounding factor. Data were shown as mean \pm SD. P values less than 0.05 were considered statistically significant. The data were analyzed using the SPSS v.15 software.

\section{Results}

This study was performed on 477 normal children including 236 (49.5\%) girls and 241 (50.5\%) boys aged $13.8 \pm$ 2.7 years old. Prevalence of low bone mass in the femoral and lumbar region was $10.7 \%$ (confidence interval of estimated prevalence: 8.2 - 13.7) and 18.7\% (confidence interval of estimated prevalence: 15.4 - 22.4), respectively. Prevalence of low bone mass in the lumbar region was significantly higher than the femoral region $(\mathrm{P}=0.012)$. Prevalence of low bone mass in the femoral region was more in 
females $(P=0.027)$, however, there was no significant difference in the lumbar low bone mass between both sexes $(P=0.417)$. These data classified by sex is summarized in Figure 1. Low bone mass in the lumbar area was associated with BMI-Z score $(\mathrm{P}<0.001)$, height $(\mathrm{P}<0.001)$, weight $(\mathrm{P}$ $<0.001)$, waist circumference $(\mathrm{P}<0.001)$, and fat mass in$\operatorname{dex}(\mathrm{P}=0.01)$. Low bone mass in the femoral area was associated with BMI-Z score $(\mathrm{P}<0.001)$ and weight $(\mathrm{P}=0.03)$. Association of low bone mass in children with their body measurements and biochemical profile is summarized in Table1. Additionally, femoral low bone mass was associated with physical activity $(\mathrm{P}=0.02)$ and lumbar low bone mass was associated with physical activity $(\mathrm{P}=0.015)$ as well as pubertal Tanner stage $(\mathrm{P}=0.041)$. Table 2 shows BMD, BMC, and BMAD in femoral neck and lumbar spine in different Tanner stages. Neither lumbar low bone mass nor femoral low bone mass was associated with sun exposure; P value was 0.37 and 0.08 , respectively. All variables with $P$ value of less than 0.2 were enrolled in a multiple regression analysis (Back ward stepwise mode). Table 3 showed the results of multiple linear regressions of associated factors with low bone mass in femoral and lumbar area, conducted by stepwise method. According to this analysis, fat mass in$\operatorname{dex}(0.047)$, BMI Z score $(\mathrm{P}<0.001)$, as well as physical activity $(\mathrm{P}=0.03)$ were associated with lumbar low bone mass and BMI Z score $(\mathrm{P}<0.001)$, and physical activity $(\mathrm{P}=0.008)$ was associated with femoral low bone mass.

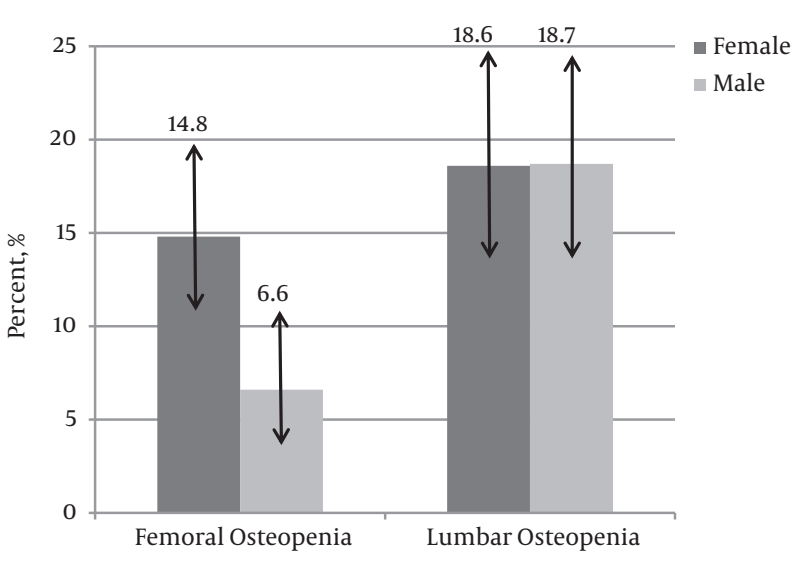

Figure 1. Prevalence and Confidence Interval of Low Bone Mass in the Femur and Lumbar Areas and Its Association with the Child's Sex

\section{Discussion}

To the best of our knowledge, the present study is the first research that evaluates the prevalence of low bone mass in normal children of the Middle East. It showed that the prevalence of low bone mass in the lumbar region (18.7\%) was higher than that of low bone mass in the femoral region (10.7\%) in children of southern Iran. Furthermore, we showed that femoral low bone mass was seen more in females, however, there was no difference between both genders in the lumbar low bone mass. Some reports from Finland (9), the Netherlands (4), United States (11), and Australia (12) also showed that bone mineral density in males was more than the females.

The present study showed that low lumbar bone mass children were shorter than those with normal lumbar bone mass; also, the pubertal Tanner stage was an important factor, however, multiple regression analysis showed that its effect might secondary to changes in BMI and body fat mass. Previous reports from Australia (12), the Netherlands (4), and Finland (9) also showed that height and puberty were 2 major independent determinants of bone mineral density in children. Furthermore, Gilsanz et al. showed that bone density increases markedly during puberty (15). During childhood, growth hormone and gonadal steroids are the most important factors in the skeletal development and bone mass turnover by stimulating proliferation and differentiation of osteoblast, which is mediated by IGF1 (19). In addition, prepubertal increase in adrenal androgens and pubertal changes in the gonadal steroids have beneficial effects on bone strength (20). During pubertal period, estrogen in both sexes could suppress the bone turnover at the endocortical surface, which leads to increase in cortical thickness (21).

Our study revealed that weight, BMI, waist circumference, and fat mass index in normal children was higher than those in children with low lumbar bone mass. Previous investigations in France $(22,23)$, the Netherlands (4), and Italy (24) also showed that bone mineral density was correlated with obesity, and fat mass. Body weight might improve bone mineralization due to the mechanical loading on weight-bearing bones (25-27). Other potential mechanisms for this positive association may be increased estrogen production in the fat tissues (28). Estrogen has an important effect on both increasing bone density and modulating bone remodeling (19).

Some studies showed good evidence that obese adolescents have more advanced skeletal maturation relative to chronological age than thinner ones perhaps because of early puberty (29). Boot et al. concluded that the Tanner stage in girls and weight in boys were the major pendent factor of bone mineral density (4).

Goulding et al. revealed that in overweight children bone mineral content and bone area were low relative to body weight (30). However, in our study after regression analysis and excluding the confounding factor, we showed that BMI-Z score, fat mass index, and physical activity were 
Table 1. Association of Low Bone Mass with Demographic and Anthropometric Characteristics and Biochemical Profiles

\begin{tabular}{|c|c|c|c|c|c|c|}
\hline \multirow[t]{2}{*}{ Variables } & \multicolumn{3}{|c|}{ Lumbar BMD } & \multicolumn{3}{|c|}{ Femoral BMD } \\
\hline & Normal & Low & Pvalue & Normal & Low & Pvalue \\
\hline Age, $y$ & $13.8 \pm 2.7$ & $13.5 \pm 2.6$ & 0.32 & $13.7 \pm 2.6$ & $14.2 \pm 2.9$ & 0.2 \\
\hline BMI, $\mathrm{kg} / \mathrm{m}^{2}$ & $18.1 \pm 3.2$ & $16.1 \pm 2.4$ & $<0.001$ & $17.8 \pm 3.2$ & $16.7 \pm 2.9$ & 0.015 \\
\hline BMI-Z score & $-0.5 \pm 1.1$ & $-1.4 \pm 1.5$ & $<0.001$ & $-0.6 \pm 1.2$ & $-1.4 \pm 1.4$ & $<0.001$ \\
\hline Weight, kg & $44.6 \pm 13.4$ & $36.8 \pm 11.2$ & $<0.001$ & $43.6 \pm 13.4$ & $39.3 \pm 12.2$ & 0.031 \\
\hline Waist circumference, $\mathrm{cm}$ & $69.6 \pm 10.4$ & $64.6 \pm 9.6$ & $<0.001$ & $68.8 \pm 10.4$ & $61.4 \pm 10.8$ & 0.37 \\
\hline Hip circumference, $\mathrm{cm}$ & $82.8 \pm 10.6$ & $76.7 \pm 8.7$ & $<0.001$ & $81.9 \pm 10.7$ & $80 \pm 9.8$ & 0.22 \\
\hline Vitamin D, ng/mL & $15.2 \pm 5.5$ & $15.3 \pm 5.5$ & 0.883 & $15.1 \pm 5.5$ & $16.1 \pm 5.4$ & 0.23 \\
\hline Calcium, mg/dL & $9.8 \pm 0.5$ & $9.9 \pm 0.5$ & 0.82 & $9.8 \pm 0.5$ & $9.9 \pm 0.5$ & 0.23 \\
\hline Phosphorus, mg/dL & $4.04 \pm 0.77$ & $4.16 \pm 0.54$ & 0.16 & $4.1 \pm 0.7$ & $4.1 \pm 0.5$ & 0.79 \\
\hline Fat mass index, $\mathrm{kg} / \mathrm{m}^{2}$ & $4.4 \pm 3.10$ & $3.1 \pm 1.3$ & 0.01 & $4.3 \pm 3$ & $3.7 \pm 1.5$ & 0.4 \\
\hline Lean mass index, $\mathrm{kg} / \mathrm{m}^{2}$ & $14.6 \pm 11.4$ & $12.9 \pm 2.1$ & 0.31 & $14.5 \pm 11$ & $13 \pm 2.3$ & 0.5 \\
\hline \multicolumn{7}{|l|}{ Sun exposure, \% } \\
\hline low & 44.3 & 49.4 & 0.178 & 44.3 & 53.2 & 0.327 \\
\hline medium & 39.4 & 40.5 & & 39.3 & 42.6 & \\
\hline high & 16.2 & 10.1 & & 6.4 & 4.3 & \\
\hline \multicolumn{7}{|l|}{ Physical activity, \% } \\
\hline insufficient & 66.5 & 79.8 & 0.015 & 66.7 & 88.2 & 0.02 \\
\hline sufficient & 33.5 & 20.2 & & 33.3 & 11.8 & \\
\hline \multicolumn{7}{|l|}{ Puberty, \% } \\
\hline Earlypubertal & 35 & 29.9 & & 37.5 & 34.9 & \\
\hline Late pubertal & 32 & 25.8 & & 31 & 25.8 & \\
\hline
\end{tabular}

the most important independent factor in preventing low bone mass in children. Similar to our report, Arabi et al., in Lebanon (11), confirmed the powerful independent effect of fat mass on the bone mineral density. Recent studies have demonstrated that WNT $\beta$ catenin signaling pathway, which plays an important role in directing osteoblatogenesis, has a key role in making a balance between myogenesis and adipogenesis $(31,32)$. Ashouri et al. showed that Lipoprotein receptor-related protein -5 (LRP5) gene, which participates in $\beta$-catenin stabilization and bone formation, may be associated with body composition; also, they showed children with heterozygote AG Genotype have lower bone density and lower total body mass. Therefore, similar to our results and most of the previous epidemiological and physiologic studies, it seems that there is a positive association between total bone mass and fat mass in$\operatorname{dex}(4,11,19,22-24,31-33)$.

In the current study, after adjustment for confounders, physical activity remained a significant predictor of low bone mass both in the femoral and lumbar areas.

Arabi et al. (11) and Boot et al. (4) revealed that exercise is a significant predictor of femoral neck bone mineral content (BMC) only in the boys $(4,11)$. Other studies also found a positive association between physical activity, especially weight bearing ones, and BMC in both Sexes (16, 34,35 ). Exercise initiating in prepubertal years appears to be the most beneficial factor in improving bone mass both at the hip as well as spine $(36,37)$, and this positive effect was sustained for about 7 months after discontinuing the exercise (38).

A limitation of our study is that we did not assess the bone age, which might be an important predictor of skeletal maturity and bone mass. Also, we could not check the various genetic factor axes (known to contribute independently to growth and puberty), and these might be the possible relevant factor. Furthermore, we have checked the 
Table 2. BMD, BMC and BMAD in Femoral Neck and Lumbar Spine in Different Tanner Stages

\begin{tabular}{|c|c|c|c|c|c|c|}
\hline Tanner & Femur BMAD & Femur BMD & Femur BMC & Lumbar BMD & Lumbar BMC & Lumbar BMAD \\
\hline \multicolumn{7}{|l|}{$\mathbf{1}$} \\
\hline Mean & 0.1404 & 0.62355 & 2.7925 & 0.65814 & 25.6872 & 0.1734 \\
\hline Numbers & 83 & 83 & 83 & 85 & 85 & 82 \\
\hline Std. Deviation & 0.02025 & 0.081839 & 0.49149 & 0.063207 & 5.99048 & 0.02194 \\
\hline \multicolumn{7}{|l|}{2} \\
\hline Mean & 0.1458 & 0.64045 & 2.8383 & 0.68989 & 70.3970 & 0.1805 \\
\hline Numbers & 60 & 60 & 60 & 61 & 61 & 60 \\
\hline Std. Deviation & 0.02196 & 0.084088 & 0.49753 & 0.071508 & 340.26591 & 0.02214 \\
\hline \multicolumn{7}{|l|}{3} \\
\hline Mean & 0.1472 & 0.67667 & 3.1298 & 0.81103 & 35.4516 & 0.1995 \\
\hline Numbers & 70 & 70 & 70 & 70 & 70 & 70 \\
\hline Std. Deviation & 0.02526 & 0.110959 & 0.60067 & 0.090619 & 8.93401 & 0.02145 \\
\hline \multicolumn{7}{|l|}{4} \\
\hline Mean & 0.1533 & 0.76748 & 3.8771 & 0.88522 & 45.4207 & 0.2094 \\
\hline Numbers & 80 & 80 & 80 & 81 & 81 & 79 \\
\hline Std. Deviation & 0.02322 & 0.113464 & 0.77498 & 0.111675 & 10.62133 & 0.02909 \\
\hline \multicolumn{7}{|l|}{5} \\
\hline Mean & 0.1599 & 0.78876 & 3.9240 & 1.00376 & 55.4302 & 0.2345 \\
\hline Numbers & 138 & 136 & 138 & 140 & 140 & 138 \\
\hline Std. Deviation & 0.02600 & 0.121748 & 0.82710 & 0.125011 & 13.99986 & 0.03342 \\
\hline \multicolumn{7}{|l|}{ Total } \\
\hline Mean & 0.1509 & 0.71380 & 3.4173 & 0.83988 & 46.6786 & 0.2050 \\
\hline Numbers & 431 & 429 & 431 & 437 & 437 & 429 \\
\hline Std. Deviation & 0.02481 & 0.127192 & 0.85061 & 0.169615 & 127.45829 & 0.03619 \\
\hline
\end{tabular}

Abbreviations: BMD, Bone Mineral Density; BMC, Bone Mineral Content; BMAD, Bone Mineral Apparent Density

sun exposure and physical activity with subjective methods; therefore this might have some bias.

\subsection{Conclusion}

The present study revealed that prevalence of low bone mass was $18.7 \%$ and $10.7 \%$ in the lumbar and femoral areas in Iranian children. Femoral low bone mass was more in females. Higher BMI-Z score, higher fat mass index, and high physical activity were the 3 most important preventive factors in developing low bone mass in children. Further studies should be done to know more important genetic and epidemiological factors of low bone mass in children.

\section{Acknowledgments}

The authors would like to thank Shiraz University of Medical Sciences, Shiraz, Iran, center for development of clinical research of Nemazee hospital, and Dr. Nasrin Shokrpour for editorial assistance.

\section{Footnote}

Conflicts of Interests: Forough Saki, Gholamhossein Ranjbar Omrani, Marjan Jeddi, Marzie Bakhshaieshkaram and Mohammad Hossein Dabbaghmanesh declare that they have no conflict of interest.

\section{References}

1. Mora S, Gilsanz V. Establishment of peak bone mass. Endocrinol Metab Clin North Am. 2003;32(1):39-63. doi: 10.1016/S0889-8529(02)00058-0. [PubMed: 12699292].

2. Ward LM, Glorieux FH. In: Pediatric bone: biology and diseases. Glorieux FH, Pettifor JM, Juppner H, editors. San Diego: Academic Press; 2003. pp. 401-42.The Spectrum of Pediatric Osteoporosis. 
Table 3. Results of Multiple Linear Regressions of Associated Factors with low Bone Mass in Femoral and Lumbar Area, Conducted by Stepwise Method ${ }^{\text {a }}$

\begin{tabular}{|c|c|c|c|c|}
\hline \multirow[t]{2}{*}{ Variables } & \multicolumn{2}{|c|}{ Low Lumbar Bone Mass } & \multicolumn{2}{|c|}{ Low Femoral Bone Mass } \\
\hline & Beta $^{\mathbf{b}}$ & P value & Beta & Pvalue \\
\hline BMI Z score & -0.485 & $<0.001$ & -0.653 & $<0.001$ \\
\hline Weight & - & - & - & - \\
\hline Physical Activity & -0.181 & 0.03 & -0.295 & 0.008 \\
\hline Sun exposure & - & - & - & - \\
\hline Sex & - & - & - & - \\
\hline Fat mass index & -0.155 & 0.047 & - & - \\
\hline Puberty & - & - & - & - \\
\hline
\end{tabular}

${ }^{\text {a }}$ Only significant data were presented.

${ }^{\mathrm{b}}$ Beta: Standardized Coefficient Beta.

3. Borges JL, Brandao CM. Low bone mass in children and adolescents. Arq Bras Endocrinol Metabol. 2006;50(4):775-82. doi: 10.1590/S000427302006000400022. [PubMed: 17117302].

4. Boot AM, de Ridder MA, Pols HA, Krenning EP, de Muinck KeizerSchrama SM. Bone mineral density in children and adolescents: relation to puberty, calcium intake, and physical activity. J Clin Endocrinol Metab. 1997;82(1):57-62. doi: 10.1210/jcem.82.1.3665. [PubMed: 8989233].

5. Mazess RB, Barden HS, Bisek JP, Hanson J. Dual-energy x-ray absorptiometry for total-body and regional bone-mineral and soft-tissue composition. Am J Clin Nutr. 1990;51(6):1106-12. [PubMed: 2349926].

6. Bianchi ML. Osteoporosis in children and adolescents. Bone. 2007;41(4):486-95. doi: 10.1016/j.bone.2007.07.008. [PubMed: 17706477].

7. Luckey MM, Meier DE, Mandeli JP, DaCosta MC, Hubbard ML, Goldsmith SJ. Radial and vertebral bone density in white and black women: evidence for racial differences in premenopausal bone homeostasis. J Clin Endocrinol Metab. 1989;69(4):762-70. doi: 10.1210/jcem-69-4-762. [PubMed: 2778034].

8. Pollitzer WS, Anderson JJ. Ethnic and genetic differences in bone mass: a review with a hereditary vs environmental perspective. Am J Clin Nutr. 1989;50(6):1244-59. [PubMed: 2688394].

9. Kroger H, Kotaniemi A, Kroger L, Alhava E. Development of bone mass and bone density of the spine and femoral neck-a prospective study of 65 children and adolescents. Bone Miner. 1993;23(3):171-82. doi: 10.1016/S0169-6009(08)80094-3. [PubMed: 8148662].

10. Bianchi ML. How to manage osteoporosis in children. Best Pract Res Clin Rheumatol. 2005;19(6):991-1005. doi:10.1016/j.berh.2005.06.006. [PubMed: 16301193].

11. Arabi A, Tamim H, Nabulsi M, Maalouf J, Khalife H, Choucair M, et al. Sex differences in the effect of body-composition variables on bone mass in healthy children and adolescents. Am J Clin Nutr. 2004;80(5):1428-35. [PubMed: 15531697].

12. Foley S, Quinn S, Jones G. Tracking of bone mass from childhood to adolescence and factors that predict deviation from tracking. Bone. 2009;44(5):752-7. doi: 10.1016/j.bone.2008.11.009. [PubMed:19103314].

13. Cassidy JT. Osteopenia and osteoporosis in children. Clin Exp Rheumatol. 1999;17(2):245-50. [PubMed: 10342055].

14. Baroncelli GI, Bertelloni S, Sodini F, Saggese G. Osteoporosis in children and adolescents: etiology and management. Paediatr Drugs. 2005;7(5):295-323. doi: 10.2165/00148581-200507050-00003. [PubMed: 16220996].

15. Gilsanz V, Gibbens DT, Roe TF, Carlson M, Senac MO, Boechat MI, et al. Vertebral bone density in children: effect of puberty. Radiology. 1988;166(3):847-50. doi: 10.1148/radiology.166.3.3340782. [PubMed: 3340782].

16. Glastre C, Braillon P, David L, Cochat P, Meunier PJ, Delmas PD. Measurement of bone mineral content of the lumbar spine by dual energy x-ray absorptiometry in normal children: correlations with growth parameters. J Clin Endocrinol Metab. 1990;70(5):1330-3. doi: 10.1210/jcem-70-5-1330. [PubMed: 2335574].

17. Faulkner RA, Bailey DA, Drinkwater DT, McKay HA, Arnold C, Wilkinson AA. Bone densitometry in Canadian children 8-17 years of Age. CalcifTissue Int. 1996;59(5):344-51. doi: 10.1007/s002239900138. [PubMed: 8849400].

18. Jeddi M, Roosta MJ, Dabbaghmanesh MH, Omrani GR, Ayatollahi SM, Bagheri Z, et al. Normative data and percentile curves of bone mineral density in healthy Iranian children aged 9-18 years. Arch Osteoporos. 2013;8:114. doi: 10.1007/s11657-012-0114-z. [PubMed: 23297104].

19. Davies JH, Evans BA, Gregory JW. Bone mass acquisition in healthy children. Arch Dis Child. 2005;90(4):373-8. doi: 10.1136/adc.2004.053553. [PubMed: 15781927].

20. Remer T, Boye KR, Hartmann M, Neu CM, Schoenau E, Manz $\mathrm{F}$, et al. Adrenarche and bone modeling and remodeling at the proximal radius: weak androgens make stronger cortical bone in healthy children. J Bone Miner Res. 2003;18(8):1539-46. doi: 10.1359/jbmr.2003.18.8.1539. [PubMed: 12929945].

21. Wang Q, Nicholson PH, Suuriniemi M, Lyytikainen A, Helkala E, Alen $\mathrm{M}$, et al. Relationship of sex hormones to bone geometric properties and mineral density in early pubertal girls. J Clin Endocrinol Metab. 2004;89(4):1698-703. doi: 10.1210/jc.2003-031113. [PubMed: 15070933].

22. Rocher E, Chappard C, Jaffre C, Benhamou CL, Courteix D. Bone mineral density in prepubertal obese and control children: relation to body weight, lean mass, and fat mass. J Bone Miner Metab. 2008;26(1):73-8. doi: 10.1007/s00774-007-0786-4. [PubMed: 18095067].

23. Braillon PM, Serban A. Bone mineral content and body composition in overweight children and adolescents. Pediatr Res. 2007;62(4):4627. doi: 10.1203/PDR.0b013e31813cbe7a. [PubMed: 17667858]. 
24. Pietrobelli A, Faith MS, Wang J, Brambilla P, Chiumello G, Heymsfield SB. Association of lean tissue and fat mass with bone mineral content in children and adolescents. Obes Res. 2002;10(1):56-60. doi: 10.1038/oby.2002.8. [PubMed: 11786602].

25. Ellis KJ, Shypailo RJ, Wong WW, Abrams SA. Bone mineral mass in overweight and obese children: diminished or enhanced? Acta Diabetol. 2003;40 Suppl 1:S274-7. doi: 10.1007/s00592-003-0085-z. [PubMed: 14618492].

26. Leonard MB, Shults J, Wilson BA, Tershakovec AM, Zemel BS. Obesity during childhood and adolescence augments bone mass and bone dimensions. Am J Clin Nutr. 2004;80(2):514-23. [PubMed: 15277178].

27. Nagasaki K, Kikuchi T, Hiura M, Uchiyama M. Obese Japanese children have low bone mineral density after puberty. J Bone Miner Metab. 2004;22(4):376-81. doi: 10.1007/s00774-004-0498-y. [PubMed: 15221498].

28. Grodin JM, Siiteri PK, MacDonald PC. Source of estrogen production in postmenopausal women. J Clin Endocrinol Metab. 1973;36(2):207-14. doi: 10.1210/jcem-36-2-207. [PubMed: 4688315].

29. De Simone M, Farello G, Palumbo M, Gentile T, Ciuffreda M, Olioso P, et al. Growth charts, growth velocity and bone development in childhood obesity. Int J Obes Relat Metab Disord. 1995;19(12):851-7. [PubMed: 8963351].

30. Goulding A, Taylor RW, Jones IE, McAuley KA, Manning PJ, Williams SM. Overweight and obese children have low bone mass and area for their weight. Int J Obes Relat Metab Disord. 2000;24(5):627-32. doi 10.1038/sj.ijo.0801207. [PubMed:10849586].

31. Prestwich TC, Macdougald OA. Wnt/beta-catenin signaling in adipogenesis and metabolism. Curr Opin Cell Biol. 2007;19(6):612-7. doi 10.1016/j.ceb.2007.09.014. [PubMed:17997088].
32. Williams BO, Insogna KL. Where Wnts went: the exploding field of Lrp5 and Lrp6 signaling in bone. J Bone Miner Res. 2009;24(2):171-8. doi: 10.1359/jbmr.081235. [PubMed: 19072724].

33. Ashouri E, Meimandi EM, Saki F, Dabbaghmanesh MH, Omrani GR, Bakhshayeshkaram M. The impact of LRP5 polymorphism (rs556442) on calcium homeostasis, bone mineral density, and body composition in Iranian children. J Bone Miner Metab. 2015;33(6):651-7. doi: 10.1007/s00774-014-0624-4. [PubMed: 25515155].

34. Thomas T, Burguera B. Is leptin the link between fat and bone mass? J Bone Miner Res. 2002;17(9):1563-9. doi: 10.1359/jbmr.2002.17.9.1563. [PubMed: 12211425].

35. Zanker CL, Gannon L, Cooke CB, Gee KL, Oldroyd B, Truscott JG. Differences in bone density, body composition, physical activity, and diet between child gymnasts and untrained children 7-8 years of age. $J$ Bone Miner Res. 2003;18(6):1043-50. doi: 10.1359/jbmr.2003.18.6.1043. [PubMed: 12817757].

36. MacKelvie KJ, McKay HA, Petit MA, Moran O, Khan KM. Bone mineral response to a 7-month randomized controlled, school-based jumping intervention in 121 prepubertal boys: associations with ethnicity and body mass index. J Bone Miner Res. 2002;17(5):834-44. doi: 10.1359/jbmr.2002.17.5.834. [PubMed: 12009014].

37. MacKelvie KJ, Petit MA, Khan KM, Beck TJ, McKay HA. Bone mass and structure are enhanced following a 2-year randomized controlled trial of exercise in prepubertal boys. Bone. 2004;34(4):755-64. doi: 10.1016/j.bone.2003.12.017. [PubMed: 15050908].

38. Fuchs RK, Bauer JJ, Snow CM. Jumping improves hip and lumbar spine bone mass in prepubescent children: a randomized controlled trial.JBone Miner Res. 2001;16(1):148-56. doi:10.1359/jbmr.2001.16.1.148. [PubMed: 11149479]. 